Interactive comment on "Seismic Hazard of L'Aquila downtown (central Italy): new insights for 3D geological model based on high-resolution seismic reflection profile and borehole stratigraphy" by Marco Tallini et al.

Anonymous Referee \#2

Received and published: 19 March 2019

\title{
General comments
}

I have read your paper with great interest and I think it is a very nice case study about the seismic hazard of downtown L'Aquila based on reflection seismic and borehole stratigraphy. You present an improved geological model for the investigation area and you have connected your results to the evolution of the L'Aquila-Scoppito Basin and the seismic hazard of this specific region. Overall the article is well structured and the topic (structural geology and geophysics, in the context of seismic hazard) is relevant for Solid Earth. I therefore recommend it for publication with revision. Although the English 
grammar could be improved and you should avoid long sentences which consist of four or even more lines. Shorter sentences will make it easier to read and understand the manuscript.

I have a few comments which are suggestions that I hope may help in improving the quality of the paper.

Interactive

comment

\section{Specific comments}

page 2 line 6: "Amplification effect related to the seismic wave propagation..." - This is a very important aspect regarding this study and therefore should be explained in more detail and you should include more recent literature.

page 2 line 15: In this part you are describing how important it is to use different geological and geophysical methods in order to get a reliable 3D model of the underground, but the cited paper deals only with shear-wave velocity profiles and ambient vibration array measurements. You should cite more papers in the context of 3D modelling that deal with the other geological and geophysical methods that you mention.

page 3 line 4: I suggest to write the abbreviations for the Scoppito-Preturo normal fault (SPF) and the Pettino normal fault (PF) in brackets as you have done for the geological formations. This makes it easier for the reader to find them in the corresponding figures.

page 3 line 5: In the text you are referring to figure 1, but in fact you are only describing figure 1b. Figure 1a shows the peak ground acceleration, which is not explained in the text. Please correct this.

page 4 line 8: Instead of "capped" I suggest to use the word "covered".

page 4 line 29: I guess that you stacked the entire recorded signal to improve the 
page 5 line 2: In seismic literature it is common to write "a maximum CMP fold of 48 traces" and not " $4800 \%$ ", because the fold of the stack is determined by the number of traces in the CMP gather.

Interactive

page 5 line 10: "Tomography data was used both to extend the seismic imaging... A seismic tomography shows velocity anomalies which do not necessarily correspond to structural features. Therefore, a reader, who is not familiar with seismic techniques, might misunderstand this part. I suggest to write one or two explanatory sentences.

page 5 line 10 to 11 : "...very near surface (first $30-50 \mathrm{~m}$ ) since usually this part is not sampled, even by "shallow" seismic reflection techniques...". The statement that the first 30 to $50 \mathrm{~m}$ cannot be imaged even by shallow reflection seismic techniques is incorrect. Many studies, especially from the last 10 years, have shown the successful application of shear wave (SH-wave) reflection seismic to image the very-near surface in high-resolution, sometimes less than $1 \mathrm{~m}$. I strongly suggest you should read some publications dealing with shear-wave reflection seismic for near-surface applications and than change this part in your text. In the following, I listed several publications which might be helpful to you:

Beilecke, T., Krawczyk, C.M., Tanner, D.C. \& Ziesch, J.: Near-surface fault detection using high- shear wave reflection seismics at the CO2CRC Otway Project site, Australia, Journal of Geophysical Research: Solid Earth, 121, 1-23, doi = 10.1002/2015JB012668, 2016.

Harris, J.B.: Application of shallow shear-wave seismic reflection methods in earthquake hazard studies, The Leading Edge, 29, 8, 960-963, doi =10.1190/1.3480010.

Kammann, J., Hübscher, C., Boldreel, L.O. \& Nielsen, L.: High-resolution shear-wave seismics across the Carlsberg Fault zone south of Copenhagen âǍ Implications for 
linking Mesozoic and late Pleistocene structures, Tectonophysics, 682, 56-64, doi = 10.1016/j.tecto.2016.05.043.

Krawczyk, C.M., Polom, U., Trabs, S. \& Dahm, T.: Sinkholes in the city of Hamburg-New urban shear-wave reflection seismic system enables high-resolution imaging of subrosion structures, J. Appl. Geophys., 78, 133-143, doi = 10.1016/j.jappgeo.2011.02.003, 2012.

Krawczyk, C.M., Polom, U. \& Beilecke, T.: Shear-wave reflection seismics as a valuable tool for near-surface urban applications, The Leading Edge, 32, 3, 256-263, doi = 10.1190/tle32030256.1, 2013.

Polom, U., Bagge, M., Wadas, S., Winsemann, J., Brandes, C., Binot, F. \& Krawczyk, C.M.: Surveying near-surface depocentres by means of shear wave seismics, First Break, 31, 8, 67-79, 2013.

Pugin, A.J.-M., Brewer, K., Cartwrigth, T., Pullan, S.E., Didier, P., Crow, H. \& Hunter, J.A.: Near surface S-wave seismic reflection profilingâǍTnew approaches and insights, First Break, 31, 49-60, 2013.

Pugin, A.J.-M., Pullan, S.E. \& Hunter, J.A.: Shear-wave high-resolution seismic reflection in Ottawa and Quebec City, Canada, The Leading Edge, 32, 3, 250-255, doi = 10.1190/tle32030250.1, 2013.

Wadas, S.H., Tanner, D.C., Polom, U. \& Krawczyk, C.M.: Structural analysis of Swave seismics around an urban sinkhole; evidence of enhanced dissolution in a strikeslip fault zone, Natural Hazards and Earth System Sciences, 17, 2335-2350, doi = 10.5194/nhess-17-2335-2017, 2017.

From my personal view and based on your seismic results, I think it would be very interesting to carry out an $\mathrm{SH}$-wave reflection seismic profile in downtown L'Aquila, because it could deliver very promising results regarding the internal structures of the sedimentary infill and the detection of hidden near-surface faults. Maybe this would be 
a nice topic for a future project.

page 5 line 18: "...less than the average travel time pick error." - What exactly is the average travel time pick error? Give a number.

General comments and or questions to the paragraph 'Seismic data acquisition':

What kind of filters were used during data processing?

Can you say anything about signal attenuation? The sweep frequency was 10 to 200 $\mathrm{Hz}$, but what was the frequency of the recorded signal.

To get a better insight into the quality of the seismic data, show some records. It would be very helpful, e.g. before/after comparison for some processing steps like amplitude correction, filtering or deconvolution.

page 6 line 16 to 17: "In the S5 borehole, a pedogenetic horizon (oxidized surface) distinguishes the FGS from the fine-grained deposits referable to MDS." - In the corresponding figure 4 you have described the boundary between FGS and MDS as an "unconformity". Please use the same terms in the text and the figures. Using different terms might confuse the reader.

page 7 line 5: use "deepest part" instead of "deepest portion".

page 7 line 30: "Its basal boundary is highly irregular, and it was recognized down to 80 ms." - In the section 'Seismic data acquisition' you have written that the first $50 \mathrm{~m}$ were not properly imaged by the reflection seismic due to the resolution limits in the near-surface. Are you sure that you can get a reliable interpretation for facies BC that is located in the uppermost part of your seismic profile?

page 8 line 3: "The calculated Vp for the tomography are different from that used for the reflection profile.." - What exactly is the difference between both velocity fields? 
Give numbers or show an image in which both velocity fields are compared.

page 8 line 15 and line 24: "ubiquitarian" - I guess you mean ubiquitous. The meaning of ubiquitarian is: relating to or believing in the doctrine that Christ is present everywhere at all times. I guess that is not what you wanted to say.

Interactive

comment

page 9 line 8 to 9: “...the evolution of infilling deposits depends on the subsidence of the basin, which is mainly controlled by the geometry of the fault systems affecting the basin." - What is with subsidence resulting from the accumulation of large volumes of sediments? In many basins we have an interaction between fault-related and loadingrelated subsidence.

page 10 line 4: “...has been drown..." - I guess you mean "has been drawn”.

page 10 line 17: “...the sedimentological characteristics of CMA point to huge events of..." - a short repetition of the most important sedimentological characteristics of CMA would be helpful at this point.

page 10 line 21 to 23: see my comment on seismic tomography and structural interpretation for page 5 line 10.

General comments and or questions to the paragraph 'Discussion':

The discussion of the tectonic features and the subsurface model is good, but what is completely missing so far is the critical discussion of the reflection and refraction seismic methods. Most of your results, except for the borehole stratigraphy, are based on geophysics. As a consequence you should discuss problems and disadvantages/advantages of both methods regarding data acquisition and processing. For example, I think discussing the resolution limits of your data would be very helpful. You should ask yourself 'What could have been done better and what other geophysical investigations would I carry out in the future, in the case of a subsequent project. 
Other questions you could think of are 'Can you compare your results with other intermontane basins in seismically-active regions?' and 'With your results is it possible to better estimate the future seismic hazard for downtown L'Aquila? For example, can you define particular risk areas, where damage to buildings and infrastructure would be higher than in other areas due to the local near-surface geology derived from your data.

\section{Technical corrections}

Figure 4: The marked "lignite level" (black line) in the stratigraphy plot is hardly visible. Maybe using a different colour, e.g. red, would be better.

Figure 5: For a better correlation of seismic and borehole results it would be nice if you could draw the location of the nearby boreholes into the seismic profile. This will help to better verify the seismic interpretation.

Figure 5: Why have you abbreviated the seismic facies twice? In the text and in table 2 where you are describing the seismic facies in detail you use BC, Ls, L, R and S as abbreviations for your seismic facies analysis. In the figure and the figure caption you use the following legend " $1=$ seismic facies $B C ; 2=$ channelized bodies in seismic facies BC; 3 = seismic facies $L ; 4=$ seismic facies $L s ; 5=$ seismic facies $R ; 6=$ seismic facies S". I understand why you had to find new abbreviations for e.g. the channel bodies in seismic facies BC, but I do not understand why you had to rename the facies classes themselves. This would be very confusing for the reader. I would rewrite the legend in the figure caption and the corresponding part of figure $5 \mathrm{c}$ like this: $\mathrm{BC}=$ fan deposits and slope breccias; 1 = channelized bodies in seismic facies $B C ; L=$ alluvial plain deposits; 4 = channelized deposits; $R$ = fan deposits and slope breccias; $S=$ meso-cenozoic bedrock; 2 = fault; $3=$ channelized bodies; $4=$ unconformity; $5=$ top of Meso-Cenozoic bedrock. This way you do not have two different abbreviations for the same facies. 
Figure 5: In the text you have written that you used a Kirchhoff time migration, but in the figure caption you have written that figure 5 a shows the "2D depth-migrated reflection of the Corso section". Have you carried out time-migration or depth-migration? You have SED also written "common deep point" but it must be 'common depth point' and instead of "two-way time" you should use 'two-way traveltime'.

Figure 7: When drawing faults into a cross section it is necessary to draw arrows indicating the fault movement.

Overall, a very nice work, congratulations!

Interactive comment on Solid Earth Discuss., https://doi.org/10.5194/se-2019-25, 2019. 